International Journal of Scholarly Papers for Media and Communications

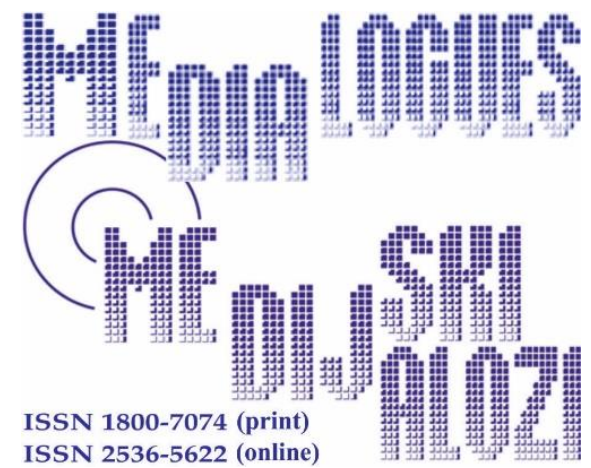

Roussou, N., Paoaioannou, T. (2021), ,Social Network Sites and Young People's Developing Identities", Media Dialogues / Medijski dijalozi,

Vol. 14, No. 4, pp. 7-28.

\title{
Social Network Sites and Young People's Developing Identities
}

NAYIA ROUSSOU, Ph.D.

Department of Communications, University of Nicosia

TAO PAPAIOANNOU, Ph.D.

Department of Communications, University of Nicosia

\begin{tabular}{|c|c|}
\hline$A \boldsymbol{R} \boldsymbol{T I C L} \boldsymbol{E}$ & Received: April 09, 2021 / Revised from: May 08, 2021 \\
$\boldsymbol{I} \boldsymbol{N} \boldsymbol{F} \boldsymbol{O}$ & Accepted: June 13, 2021 / Available online: October 15, 2021 \\
\hline $\boldsymbol{D O I}$ & doi.org/10.14254/1800-7074/14-4/1 \\
\hline
\end{tabular}

\section{ABSTRACT}

The present research aims at finding out how young people are possibly affected in the continuing formation of their sociocultural identity by their use of social websites such as Facebook with a focus on the following areas: online/offline relationships, online/offline participation in civic activities (international or national), online/offline consumership, and online/ of-fline pursuit of professional goals. The 
study also probes attitudes toward other cultural groups, the Turkish Cypriots in particular, and possible future co-existence with them, in light of a still divided Cyprus. Based on 27 semi-structured individual interviews with students of the University of Nicosia, the results revealed that while the majority of the respondents used Facebook, some consciously chose not to be on Facebook. As to consumption, traditional media advertisements seemed to prevail, although online purchasing is gaining popularity particularly through websites such as Amazon.com or e-bay rather than under the influence of Facebook advertisements. The results also showed that there was a lack of trust in political parties and institutions, all created in Cyprus during its last 50 years of independence. As to online/offline civic activities (Causes on Facebook), there was a preference of local causes over global issues and avoiding to contribute to the public sphere offline. Moreover, it appeared that social sites were primarily used to strengthen offline social networks. The results on Otherness and more especially, the Turkish-Cypriot "Others", revealed that most students stressed their preference for Greek Cypriots as friends and admitted of thinking in terms of "us" as the Greek Cypriots, and "them" as the Turkish Cypriots.

KEYWORDS: New media, facebook, communications, identity development, Youth, Cyprus.

\section{INTRODUCTION}

Since their inception, social network sites such as Facebook, MySpace and Twitter have become increasingly popular. With these sites, not only are people able to communicate with their friends and families without geographical barriers, but also connect with strangers based on shared interests, or common language, or shared identities. While these sites appeal to different languages and countries, and their popularity changes over time, according to Web-Strategist.com, about 400 million people around the world actively use Facebook, and almost half of them use Facebook every day. Furthermore, about 55\% of the users ages between 12-17 have created profiles on social network sites, and this percentage is increased to $64 \%$ of teens between 15-17 (Boyd, 2008).

As young people are extensive users of Internet-based technology, recent studies focusing on young people and their consumption of the Internet have high- lighted a wide range of social issues, with a growing recognition of the impact of youth Internet use on their identity development. This research aims at finding out how young people are possibly affected in the continuing formation of their socio- cultural identity by their use of social websites such as Facebook with a focus on the following areas: creating virtual relationships versus actual offline relationships, awareness and possible online and offline participation in civic activities (international or national), political awareness and participation, cyber consumership versus of-fline consumership and possible pursuit of professional goals online versus in real 
life. The above areas have been chosen as some of the core components of ethnicity and lifestyle essential to the contemporary socio-cultural identity of young people.

\section{SOCIAL NETWORK SITES AND FACEBOOK}

Boyd and Ellison (2008, p. 2) define social network sites as "Web-based services that allow individuals to: - construct a public or semi-public profile with a bounded system - articulate a list of other users with whom they share a connection - view and traverse their list of connections and those made by others within the system". While network sites vary in their ability to incorporate new technologies such as mobile connectivity and blogging, their main technological features are fairly standard. The key element consists of visible profiles that display a list of chosen friends who are also users of the site. The profile is created based on answers to questions such as age, location, education and interests. Facebook also encourages users to add photographs and multimedia content to enhance their profiles. Users can update their profiles anytime and notify their friends about the changes. Network sites also have security/privacy features which affect the extent of visibility of users' profiles. MySpace lets the users decide whether their profile can be viewed by the public or friends only. On Facebook, users can join networks organized by parameters such as city of residence, workplace or school, and Facebook allows users to choose whether they give others belonging to the same community access to their profile.

In addition to creating profiles, users are asked to identify others in the system who are in their offline social circles under the terms "Friends", "Contacts", or "Fans". The public display of the friends list is crucial as it enables viewers to traverse the network by clicking through the lists. Most network sites also allow users to leave comments on their friends' profile or send private e-mail messages, similar to most webmail applications. Facebook has the applications of the Wall, Pokes and Status. The Wall is a space on every user's profile page that allows friends to post messages for the user to see; Pokes allows users to send a virtual "poke" to each other, and Status lets users to inform their friends of their whereabouts and actions. Depending on privacy settings, anyone who can see a user's profile can also view that user's Wall and Status.

Additionally, Facebook has the Facebook Platform, a framework for software developers to create applications that interact with core Facebook features. These applications range from Gifts, allowing users to send virtual gifts to each other; Marketplace, allowing users to post free classified ads; Events, letting users inform their friends about upcoming events; and Video, letting users share homemade videos with one another.

Facebook has also opened up a new realm of possibilities with the Causes application. The Causes application enables members of the Facebook community to 
join together, recruit supporters, and donate money to thousands of different charity or- ganizations, relief groups and political campaigns. The idea behind Causes is to take advantage of the vast circles of online friends connected through Facebook to reach potential donors and volunteers on a more personal level. Since the launch in May 2007, 60 million people have started using Causes and over 250,000 causes have been created about every topic from halting global warming to supporting arts education, and the application has raised $\$ 9$ million overall. The Causes claims that this application essentially democratizes activism by empowering users of Facebook who want to leverage their network on Facebook to effect positive change. Any Facebook user can create a cause, recruit their friends into that cause, keep everybody in the cause up-to-speed on issues and media coverage related to the cause, and, most importantly, raise money directly through the cause for any U.S. registered nonprofit or Canadian registered charity.

\section{BRIDGING ONLINE AND OFFLINE SOCIAL NETWORKS}

While social network sites help users to establish and make visible their social networks, and connections between strangers can be made, these sites are primarily used to communicate with people who are already in their offline social network, central or peripheral. Ellison, Steinfield and Lampe (2007) analyzed Facebook as a convenient and effective means of maintaining and solidifying existing offline social circles. Online friends usually share some common offline relationship albeit these online friendships may be weak. Online and offline interactions interface in such a way that Facebook users search for people who are already part of their social life more than browse for strangers to expand their social experience (Lampe, Ellison and Steinfield, 2006).

\section{DIGITAL MEDIA AND FOSTERING CIVIC PARTICIPATION}

Research on the role of media in youth civic participation has argued that the traditional approach to examining media and civic participation considers youth as a passive audience and has largely focused on media effects and formal political participation (Bell, 2005). Instead of communicating through the mass media, many young people are turning to digital media for information. Researchers are encouraged to look to ways in which young people make selective use of media, particularly new digital technologies, and incorporate media content into their lives in civic ways. As the Internet has provided a new way of creating communities that extend beyond geographic boundaries (Kraut et al., 2002), it can be a new venue for youth to engage in civic and volunteering activities across local communities and national frontiers, to learn about political life and to experience the challenges of democratic participation (Camino and Zeldin, 2002). 
The possible effect of social network sites on mobilizing youth, or rather the Facebook effect on the American political system, became clear in 2008, as Facebook teamed up with $\mathrm{ABC}$ and Saint Anselm College to allow users to give live feedback about the "back to back" Republican and Democratic January 5th debates. Facebook users could participate in debate groups organized around specific topics, register to vote and send in questions. Over one million people installed the Facebook application - US politics. The "Facebook effect", as Newsweek calls it, demonstrates that social network sites can increase youth mobilization in election season by creating a way for students to share and access campaign information and support candidates.

As discussed before, the Causes application on Facebook has also become a new tool to involve people in charity and volunteering activi-ties. According to AllFacebook.com, Causes has 6,244,688 weekly active users and 23,578,039 monthly active users. Facebook users can participate in recruiting, spreading awareness, leading dialogue, signing petitions and fundraising from ot-hers. In addition to individual activists, nonprofit organizations have also used Cau-ses to build communities of supporters around the issues they work on. And a num-ber of causes directly address youth related issues or try to appeal to youth. Red Cross Youth, for example, has 154,359 site visitors who have registered themselves in the Red Cross database as future volunteers.

While this evidence demonstrates the potential role of social network sites in facilitating civic engagement, some have gone as far as suggesting that a 'Youth civic culture' is emerging on the Internet (Montgomery et al., 2004), Livingstone cautions that "a few studies are charting interesting initiatives using the Internet to stimulate young people's participation, holding out the promise of new opportunities through instances of 'best practice', although it remains unclear how and by whom these could be evaluated or more widely implemented" (2003, p. 151). More research apparently is needed to assess youth civic engagement - looking to see what activities and issues interest youth, what participating venues youth seems to prefer, and whether they are engaged in different ways than previously thought.

The diversification and pervasiveness of the media today are one strong source of meanings and influences which cannot be ignored. More especially, discussing directly youth and online/ offline civic and community participation and about their perspectives on related issues, such as politics and activism, will help to develop further understanding these issues in such a way that values youth participation. On the other hand, Hafez (2007, p. 113) believes that "People who spend a lot of time romping around in the global spaces of the Internet can expand their knowledge of the world in all directions. But there is no guarantee of authenticity." And the present research attempts to obtain indications as to where Greek-Cypriot youth stands in relation to these contradictory, at times interpretations of young people's relationship with social websites in particular. 
Of course, it must not be left unsaid that social websites themselves, and Facebook in particular, have been topics of contradiction. Facebook has been blocked intermittently in several countries including Syria, China, Vietnam and Iran and has also been banned at many places of work to stop employees from wasting their working time. "Privacy", according to Wikipedia (http://en.wikipedia.org/ wiki/Facebook), has also been an issue and it has been compromised several times. On another, even more serious account there have been warnings, like that of Roman Catholic Archbishop of Westminster Vincent Nicholas, England's top Catholic bishop, that Facebook and other social network sites may lead teens to commit suicide, with the Archbishop warning that "social networking sites can damage intimate relationships and leave teenagers without strong social ties" (Ibid).

\section{ONLINE CONSUMERSHIP AND PROFESSIONAL PURSUITS}

Consumption in today's society has a significant impact on and meaning for the individual: it becomes a means by which people communicate and interact. "Consumption is part of children's and young people's education and socialization, and plays a role in the development of identity and self-image" (Benn, 2004, p. 108). Although encouraged to be informed and rational consumers, with the availability and easy access of online commerce, consumerism is likely to be foremost characterized by globalization. And social network sites can be used to promote particular aspects of consumption connected to both material and non-material aspects of life. Facebook launched Gifts on February 8, 2007. This allows users to send virtual gifts to their friends that appear on the recipient's profile. Gifts cost $\$ 1.00$ each to purchase and a personalized message can be attached to each gift. Additionally on May 14, 2007, Facebook launched Marketplace, which lets users post free classified advertisements, an additional consumer service, besides the advertisements listed in its pages linking the user to different relevant sites for ordering goods. Job information also seems to be available on Facebook as different employers may advertise their personnel needs and vacancies, different groups may be involved in providing job and professional information and ad links may also lead to job advertisements.

\section{THE PRESENT RESEARCH PROJECT}

In Cyprus, $82 \%$ of the population aged 16-24 has skills in using the computer and the Internet (Eurostats, 2009). A study conducted on college and university students in Cyprus (Papaioannou and Roussou, 2009) has found that about $89 \%$ of the student population access the Internet everyday, resulting in an average time of 2.2 hours on the Internet daily. With regard to social network sites, whereas information from the Internet as to the use of "My Space" in Cyprus does not seem to be forthcoming, figures as to Facebook use in Cyprus (www.allfacebook.com) appear to be quite informative from different angles, as follows: Number of users on Facebook in 
Cyprus: 258060 Number of male users on Facebook in Cyprus: 133380 Number of female users on Facebook in Cyprus: 113580 Penetration in Cyprus: $23.79 \%$ Online penetration in Cyprus: $77.03 \%$ Further information as to age-group use of Facebook in Cyprus gives us the following percentages:

\section{User-Age Distribution - Facebook Cyprus}
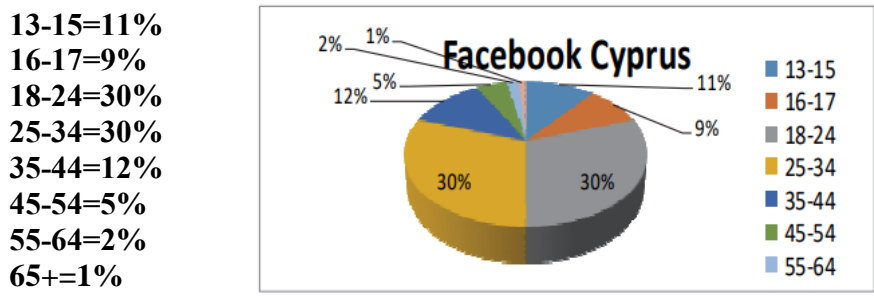

The fact, that the biggest percentages of Facebook users - 30\% - are age groups 18-24 and 25-35 was very good justification for exploring the issue of social websites and young people's developing identities. Use of the Internet and social websites in particular have been reinforcing the theory of social and cultural globalization, a spirit-of-the-times development which essentially bears on the transformation continuum of collective consciousness into social representations.

The term "collective consciousness" (http://en.wikipedia.org/wiki/Collective_ consciousness) seems to be going from "solidarity attitudes and memes" to "extreme behaviours like groupthink or herd behaviour." It has developed as a way of describing how an entire community comes together to share similar values. According to Castells (2004, p. 57), on the other hand, it is proposed that "formally, a representation can be characterized as the relation between three elements: subjects, or carriers of the representation; an object, activity, or idea that is represented; and a project of a social group within which the representation makes sense." Many thinkers of course admit that the theorization of social representations was inspired by Emile Durkheim's notion of collective representations.

How much then do social (collective) representations go into the making, the shaping and reshaping of young people's identities today, in the context of a territorialized historicity versus the regular and extensive use of social websites that offer them common experiences, activities, projects, ideas and challenges? An impressive scale of life experiences to entertain, to train in sharing to train in communication transborderwise? A lived world - online/offline - with specific themes that await to be conceptualized in the lifestyle of young populations?

These are common questions that matter for all youth today. For Cyprus youth, they are more significant, as the island has been invaded, partitioned and semi- occupied for more than one generation now -37 years. A period during which the two 
main ethnicities in the island - i.e. Greek-Cypriots and Turkish-Cypriots have been living in territorially divided areas. Ethnicity is a powerful pillar of national, social and cultural identity. According to Manuel Castells (2004, p. 57) "ethnicity is being specified as a source of meaning and identity, to be melted not with other ethnicities, but under broader principles of cultural self-definition, such as religion, nation and gender". On the other hand, the historical context in which people develop and progress plays a very important role in shaping the collective memory of people. These reasons provide additional challenge for looking into the identity and the collective aspirations, lifestyles and empowerment of young people in Cyprus today, as a recent bi-communal research report conducted by the University of Nicosia and the Cyprus Social and Economic Research Centre (KADEM) did recently (Overview, 2009: United Nations Development Programme, "Youth in Cyprus: Aspirations, Lifestyles \& Empowerment",hdr.undp.org/en/reports/nationalreports/cyprus_hdr 2009 en.pdf). The research was conducted between 2007-2009, as a part of the Youth Dialogue Projected supported by the United Nations Development Programme, and even though some of the conclusions of this report may not bear directly on the present project, they do give us an idea of the profile of Cypriot youth. With regard to the identity of young Cypriots, the researchers consider that:

- "The issue of identity among Cypriot youth is neither simple nor clear-cut and is complicated by the island's history of colonization, identification with the respective 'mother countries' and the enduring division between the two main communities."

- So approximately two-thirds of youth from the two communities felt more "Mediterranean" than "Middle Eastern or European".

- A closer examination of what the term "Cypriot" signifies to young people highlights that, a striking $86 \%$ of Greek-Cypriots and a corresponding 55\% of Turkish- Cypriots, when using the term "Cypriot" refer exclusively to Greek-Cypriots or Turkish-Cypriots, respectively. Thus, the term Cypriot seems to be used by most young people as synonymous to their own ethnic community and not to all Cypriots.

Further findings in this report indicated that the family still has a strong hold on young people, a fact that may need to be more balanced with the individual empowerment of young people and that many young people in Cyprus feel they are cast in the role of subordinate citizens by the political agendas of political parties and institutions.

\section{OBJECTIVES}

The present research aimed at exploring the different dimensions of the developing identities of Cypriot youth, in modern Cyprus, a member of the European Union, in the context of their historical and geographical realities, in association with 
the use of social network websites such as Facebook and possibly My Space, even though from existing statistics the second one does not seem to have many users in Cyprus. Gannouchi, in Castells (2004, p. 13) reminds us that "the only way to accede to modernity is by our own path, that which has been traced for us by our religion, our history and our civilization". Circumstances being what they are as we saw above, identity is a challenging theme especially among the developing young population of Cypriots today. This challenge was treated by the present researchers in two previous studies, quoting from which will further place the present research in focus.

In a research paper entitled "The Internet and Young People's Sociability: Continuums or Reversals?" (2006), one of the main findings associated with the socia- bility of young people was that "spending more time online would lead to more discussions with friends and wanting to belong to a club or society, but also increased verbal aggression and a tendency for depression"(p.203). In a second research project on "Young People and New Communication Technologies: Cross-media Consumption and its Effects on Cognitive and Affective Development" (2008), some of the con clusions seem to be of interest to this study: In spite of Europeanization and globalization, the celebration of the end of nationalism, as mentioned earlier, seems to be premature" (p. 256). And "One of the most worrisome aspects though in the results of this survey which deserves further research is young people's avoidance to contribute to the public sphere in real life, as very few seemed to be active in any specific social, political, or cultural areas" (p. 264). The focus in this project being identity of young Greek Cypriots, in association with the use of social websites, especially Facebook, it was considered worthwhile to attempt tracing any possible elements of "collective" identity, as Melluci in Escobar (1992, p. 72), defines it, "a shared understanding of "what we can and will do", or whether inspite of the common use of social websites like Facebook where communication can be frequent, ubiquitous and systematic, this sense of collectiveness or group identity lacks in depth or continuity, either online or offline. Additionally, to repeat wellaccepted statements, from the sociological point of view, identities are considered to be constructions, and as Castells (2004) proposes they can be constructed from materials of history, geography, biology, productive and reproductive institutions, collective memory, personal fantasies, power apparatuses and religious revelations.

\section{METHOD}

Having a backdrop of research with a statistical thrust more than a qualitative approach, it was considered that a qualitative approach through an openended conversation with each interviewee would be used. Such effort to investigate trends, tendencies, or even indications as to the identity of young users of social websites could give us a different perspective perhaps to the identities of young Greek Cypriots. Even though interviews may lack in generalizability, they can give the opportunity to the interviewees to talk about their lived world, express their views 
and opinions in their own words and talk about their hopes and their expectations in life. Again even if qualitative interviewing lacks in the confirmation of quantitative data validity, they offer the interviewer (and the wider public) the opportunity to understand the world from the subjects' points of view, to unfold the meanings of people's experiences, to uncover their lived world prior to scientific explanations (Kvale, 1996). And as the objectives of the present paper are theme-oriented, the personal interview was considered a suitable research technique to investigate the feelings, the meanings and the inter-relations between online and offline conceptualizations connected to the developing identities of young people.

A series of interviews were conducted with students of University of Nicosia, aged between $18-25$. Twenty-seven students were chosen at random, 17 female and 10 male. The sample included one Turkish Cypriot and four exchange students studing in the Erasmus programme. Seven were M.A. students and 20 were undergraduate students.

The agenda of questions was semi-structured, with diversions in the dialogue between the interviewers and the interviewees, as the construction of their life world realities had to be made through the linguistic conversations which sought to dialectically cover, as mentioned in the introduction of the present paper, but were not limited to the following areas:

- Use of Facebook and My Space, vs. other media, especially television,

- Habits of consumership,

- Job searching and advancement of professional development,

- Voting and political participation,

- Participation in civic and action groups,

- Online and Offline,

- Attitudes towards Turkish-Cypriots and other cultures in the island,

- Attitudes towards a future co-existence with Turkish Cypriots in a unified state.

The above areas (or themes of conversation) were chosen as important aspects of the lifestyle and behaviour of young people in Cyprus today, in the particular political and technological culture in which they have to adapt and grow, with a continuous effort to situate dialectically their human activities in a social and historical context. Cyprus culture today is going through a period of tension and transition for all the population, but is certainly more taxing for young adolescents who are called to move on from the status of an islander to that of a European citizen, from a state of their country's partition to a plausible solution of the Cyprus problem, and from the analog media of radio and television to digital technology and the ever enlarging embrace of Internet-based communication technologies.

Numbers in personal interviews are of no primary consequence, but the qualitative text which may develop can impart to the reader the feelings and attitudes of 
the interviewees as well as their conceptualization of the practices to which they confess and about which they discuss with the interviewer. So it is the responses and the interpretations of phenomena which are explored in the entire framework of the objectives established by the research.

\section{INDICATIONS AND FINDINGS}

\section{Use of Facebook and My Space}

Initially it was established that: 21 out of 27 do not use "My Space"; 5 never use Facebook; 22 use Facebook and 3 do not watch television.

\section{Consumership}

The types of products they usually buy are the following:

\section{Online:}

Clothes, tickets, books, books from Amazon.com, electronics, gifts, flowers, shoes, watches, jewelry, and DVDs and CDs from e-bay and from Amazon.com

\section{Offline:}

Fashion, shoes, bags, jewelry, food, bus and air tickets, and university books

Some of the problems they mention in buying online are issues of security, theft, having a credit card (which some do not) and they also seek confirmation from friends, before ordering. Most of the responses about following sites of ads in Facebook were negative. But they do buy from online ads: "If I buy online, I go to e-bay or Amazon. Still I buy more offline. But online shopping is a good alternative for me"1. "No, I have never bought anything through Facebook. I don't trust the companies advertised there. I am thinking of getting an internet card to use only for the Internet." "I have noticed those ads. But never bought anything. I don't believe in the Internet. I don't think it is reliable. Yes, I have heard people buying from Amazon.com, but never tried myself." And "I have never bought anything from Facebook but I used to buy books from an Italian website. Books that are difficult to find. I prefer to buy things offline because I like to see physical things. I prefer to go to stores and touch things, even for books."

The above tenor was almost uniform throughout all the answers as to online shopping. Physical contact with the products seemed to be preferable for most interviewees and some went so far as to say that if they spent money buying online things which were no good, their "dad" could be "mad", reminding us of the strong ties in

\footnotetext{
${ }^{1}$ All the comments and quotes are taken from the series of interviews given to the authors, Nayia Roussou and Tao Papaioannou recorded during December, 2009.
} 
the Cypriot family today and the need for more empowerment and independence of young people. The epitome about buying online versus offline is summed up in the following two lines, perhaps: "You can't always trust online advertising. You need to see the products with your own eyes".

\section{Pursuing Job Interests}

Some respondents did check the internet for either short-term jobs or for professional employment.

Three mentioned JOBCYPRUS.COM, while one interviewee was trying to build his own blog. One felt that he "was not comfortable putting his CV online" in an effort to find a job and another one mentioned that some of his friends found jobs like playing in a band or working in a coffee-shop, while a third one found a job in modeling. The whole discussion brought to the surface a general distrust in job advertise- ments online, except for the Cyprus government site, from which one respondent got a job in the police force. They looked for jobs more offline, in the traditional media of newspapers or magazines, even though one interviewee stated that she was amazed that some of her classmates in Cyprus only used newspapers and magazines as sources for jobs.

\section{Voting and Civic Engagement, Online and Offline}

Sixteen interviewees stated that they vote systematically in political elections and a good number stated that they belong to either online or offline groups. Very few belonged to both. More analytically, as to voting decisions, there was a generally strong feeling that somebody who "respects" his or her country must vote, or they would vote "to make sure that the suitable person gets the position". But that was the main interest of the sample in the political life of the country. They mainly avoided belonging to political parties, with about two exceptions and were critical of political leaders and institutions, in a very direct and critical manner: "I am against political partyism, because I don't believe they can be of any help to you or to any campaign. The political groups care about promoting their party above all and usually lead to nationalism." But the only Turkish-Cypriot participating in the project was very definitive about political affiliations, in his answer about political involvement, in contrast to his voting habits, for which he had good reasons: "Yes, because I have always been interested in politics, I join these groups in real life as well. No, I have never voted in elections. I live in the Northern side of Cyprus and there is Turkish control from Turkey".

\section{Online Group Involvement:}

Inspite of the respondents' disinterest and distance from political involvement, they seemed to be positive in participating in philanthropic activities online such as 
joining groups on violence against women, minors and animals, groups about health issues, cancer patients support groups, or signing petitions as in the case of the stealing in December, 2009, of the corpse of the late Cypriot president, Dr. Tassos $\mathrm{Pa}$ - padopoulos. Two were also active (one on the waning side) in Greek-Cypriot/ Turkish-Cypriot rapprochement groups. Offline they seemed to contribute to philanthropic money errands, blood donations, recycling, the Red Cross, AIDS support groups, the bi-communal platform, and animal and environment protection groups, while three respondents stated they had personal hobbies like writing verses (and joining a relevant online group) or dance and theater activities. Their civic participation did not seem to extend to global "Causes", either on Facebook, as a social website, or on any other appropriate sites, where global issues such as starvation of children, or crucial environmental or economic issues were dealt with. Their public sphere interests seemed to be limited to their local realities and possibilities with an absence of a "campaigning" spirit either online or offline.

\section{Relationships with Turkish Cypriots}

The interviewees seemed to have met either in the university, or earlier in life with Turkish-Cypriots, but the theme running throughout the interviews was one of skepticism and mistrust, not so much because of the young people themselves, but because of the events that had occurred in 1974.

Paradoxically enough, their meetings with Turkish Cypriots were in real life not online - online, they chose not to keep contact with them, even though they could have done so fairly easily. Apparently because of (admitted) prejudice in many of their statements which we propose to look at in the section that follows on the discussion of the results and indications derived from the 27 interviews of the project.

\section{DISCUSSION OF RESULTS AND INDICATIONS}

The method chosen for this exploratory research project, as stated already, does not depend on statistical data, as the sample was too small for any statistically meaningful or valid conclusions. But this being a qualitative research report, the intensity, the phraseology and the frequency of the statements made by the interviewees provide a background which can give us indications of how young adolescent Cypriots formulate their identities today in a changing world and in a changing Cyprus, with the active inclusion in their life world, of online social websites like Facebook.

Cypriots, because of their geographical location and their multiple community constituents, have always had the tendency to have multiple identities. But on the Greek-Cypriot side, through different research projects in the last ten years, more especially after the invasion and occupation of Cyprus by Turkey in 1974, one can 
observe a gradually crystallizing identity which came through in this series of interviews as well.

The interviews established, for a start that the majority of the interviewees (22 out of 27) use Facebook and the majority again (21) do not use My Space.

Quite a number (14) do buy online but most do it through other websites like ebay or Amazon.com, not through advertisement links on Facebook. But both those who buy online and those who do not, have expressed strong reservations as to purchases on the Internet with regard to quality of products, safety of ordering without having a corporeal sense of the product and the disadvantages mostly, versus the advantages of ordering online, instead of buying locally.

Not many tried to find jobs online and even those who did only used the official government site or confessed to finding subsidiary jobs, like offhand modeling or serving coffee in a café or playing in a band. Regarding their interest and participation in different causes online, ten of them were involved in different groups on issues, for example, protection of animals, the Red Cross, anti-cancer, Internet addiction, protection of the environment. Interestingly, there was one group that aimed at collecting signatures about the stealing of the corpse of former Cyprus president Tassos Papadopoulos; the Turkish-Cypriot inter-viewee was with groups with political interests and an exchange student from the U.S. with a "Back to School supply" charity collection in his own country. These interview- ees were not involved in relevant or other civic activities or causes offline, except for the Turkish-Cypriot and one Greek-Cypriot who are also involved with political groups offline.

Some of the comments of those interviewees who do not join causes online are worth noting: "Causes, I don't find them interesting." Or: "I guess I like to be approached instead of seeking out people interested in common causes with me." "I don't see the point. What I do and what I contribute don't go well with those (environmental) groups on Face-book...I don't think they are useful. There is usually no interaction and you are just a member." "I always give money to Radio Marathon. This is better than donating money online. You see where the money is going. The exchange student from the U.S. pointed a finger at older people running organizations: "I also belong to a breast cancer group in real life aside from causes and philanthropic events online, although I don't directly work with them. I prefer to establish a cause on my own. When you work with these organizations run by older people, they are used to working in certain ways, I'd like to go above and beyond."

Contrariwise, some were in favour of online involvement, not offline: "Online, yes (belonging to groups) but not offline." "I'm too tired when I'm done with my work and clicking buttons is easier." And political involvement even though very rare, when pre- sent, was expressed both online and offline: "Yes, I do belong to a political party and I also join it on Facebook. It is easier on Facebook as you decide the hours you are go- ing to contact the group yourself, as you may be busy with different things during the day." 
This lack of political interest and participation seems to resonate the conclucion of Hafez (2007, p. 100) that "there is a chasm between increasing international interac-tion and the Net's meager political relevance and power o mobilize. This web creates a virtual world which often lacks a corresponding real-world counterpart."

On another account, one interviewee (an M.A. student) belonged to a group where they managed their own restaurant and graded each other for the plates they served. She started off with 800 friends and then limited them to 140, but couldn't really live without Facebook, her corporeal friends being very limited. Actually at one point she paused and asked: "Do you think this is a psychological thing?" Another inter-viewee (a working professional) had a virtual adopted fish pet which she fed regularly, but confessed to loving her actual house pet more than the virtual one. One would wonder if they did reveal their real identity on Facebook during these activities.

The general feeling one gets from the self-stated interests of the interviewees in participating in organized civic interest groups or organizations is a negative impression. This lack of interest of course on behalf of young people in civic activities is today a world phenomenon. In Cyprus it has also been established by the Cyprus Human Development Report (2009, p. 87):"The largest percentage of participants by far (55\% of Greek-Cypriots and 48\% of Turkish-Cypriots) admitted that they did not actively participate in any organization or association."

Regarding the political interest and involvement of the interviewees in the political life as expressed in voting, out of the 16 who stated voters, some of the inter- esting comments were as follows: "If you respect your country, your traditions, give your opinion through voting." "In Cyprus, if you belong to a political party you don't want to publicly show it. It will limit your career." An exchange student said: "I used to vote, not now, as I have been away from my country for some time."

Some voted what their parents did, some were independent in their voting decisions.

Nine interviewees stated they belonged to groups only offline, but aside from two who were involved with bi-communal activities and two with politics (both online and offline) the rest were involved with dancing and the theater, blood donation, radio marathon donations hobbies, protection of animals and the environment, recycling, breast cancer activities. A mixture, in other words, of personal interests and civic engagement on a transitional basis. As to their relationships with friends online and offline, most of them, even those who had many friends online, expressed their clear preference for their offline friends and for Greek-Cypriot friends, as well as pointing out that their friends online were mostly people they also knew or had met anyhow in real life: "I would say I have deeper friendly feelings for my real life friends, as we go out together, we meet socially, there is more trust in them, as we meet face to face." "I don't have many friends online. My friends are around me, in real life. They are mostly Cypriots and they are from the university. I have also met 
some who came from Texas, America in the Erasmus programme and we talked about how they live there." "I don't make friends on Face-book whom I do not know. Even the international ones are people I met first in real life."

All the above is consistent with existing research evidence on the interfacing of online/offline friends and contacts in that online and offline interactions interface in such a way that Facebook users search for people who are already part of their social life more than browse for strangers to expand their social experience (Lampe et al. 2006).

Regarding the use of MSN and whether the interviewees knew all the people on MSN: "Yes. Whether I met them recently or knew them before, I know them all and they are all Greek Cypriots". An interviewee who doesn't use Facebook at all said she is not inter- ested in the site: "I have friends and I talk with them and I see them." "I have 13 friends who are on Facebook and I know each one of them well and I see them offline. You can ignore people online easily, but not so offline. I don't trust people easily". The Turkish-Cypriot interviewee said: "I have never tried to meet Greek-Cypriot s online.... I have never asked my Greek friends if they are on Facebook and they have never asked me." One of the exchange students commented: "Most of my friends are Europeans, North Americans and Arabs. No, I don't have many Cypriot friends. They don't seem to want to interact much. I sometimes feel that they are a bit stuck up. I also don't care to have a lot of friends on my friends' list to show off." Several interviewees (a minority of 4-5) stated as having online friends they haven't met in real life, non Greek-Cypriots as well, including Americans, Europeans, Canadians, Chinese, and Spanish.

\section{RELATIONSHIPS WITH TURKISH-CYPRIOTS}

Perhaps the most striking sequence of the group's answers because of its homogeinity was the sequence about Otherness, and more especially, the Turkish-Cypriot "Others",and about feelings of ethnicity or nationalism, the situation of division in Cyprus being what it is. All Greek-Cypriot interviewees -25-admitted to thinking about "Them" and "Us" re the Turkish Cypriots and themselves and some did not hesitate to elaborate with different statements:

- "Yes. Yes. Maybe it is wrong, but often enough. Especially after the opening of the barricades to northern Cyprus (in 2004) they (Turkish Cypriots) come over and take our jobs." "Yes, I do find myself thinking about "Me and the Others" - the Turkish Cypriots. In my party (political), there are people who are extremists and I am not anyhow, one of them. I haven't gone to the occupied areas however and do not intend to go. Yes, I feel to a great extent that my identity is territorial. It is connected to the part of Cyprus in which I live."

- "Yes, I have two Turkish-Cypriots on Facebook, but I have never met any Turkish Cypriots in real life...I have some prejudice against them, one might say, 
from what I hear from my parents...Yes, I do find myself thinking in terms of "We" and the "Other" Turkish Cypriots and I can say I feel racist enough. I believe we are superior to the Turkish Cypriots, we have more justice."

- "Yes, I met 2 or 3 Turkish Cypriots online, but not in real life and even though I believe in co-existence with Turkish-Cypriots, I have never visited the occupied part of Cyprus."

- "I have not met any Turkish-Cypriots online and no, I am not interested in doing it, as I don't think we have anything to say and I am not interested in making an effort to meet them. If I happen to meet somebody and he turns out to be a good person, I could change the image I have in my mind about him. Some of them have problems with us but it doesn't mean that they are all like that."

- "To a certain extent we can live with them, but yes I do think of "Us" and "Them" and I haven't visited the occupied areas. I don't want to show my ID or passport to enter my own country. I believe my identity is pan-cyprian, but you go to the barricades with your ID card as a Cypriot citizen coming from the whole country and you are turned into a Cypriot visitor of the occupied areas, where there are occupying armies."

- "I don't feel strongly about other cultures in Cyprus, but there are many things separating us from the Turkish Cypriots. To co-exist with them, would be very difficult. Only if the factor of religion becomes less powerful. Language too, but mostly religion. Can you imagine Christmas time, having to answer a 3-year-old child, why you have a Xmas tree while his little Turkish Cypriot friend doesn't have one? This is very crucial in our lives, I believe."

- "No, I don't want to present my passport, I don't recognize them."

- Here is an excerpt with very strong views on Otherness that resonates the views of the majority if not of all the interviewees.

Do you know any Turkish Cypriots? Yes,

I know a girl. What do you think of her? Her views are more similar to ours, than the view of a Turkish girl. (Presupposes that the views of a Turkish girl are radically negative). level.

Do you believe that we can co-exist with the Turkish Cypriots? Yes, on a general

I personally however, believe that it would be difficult, as we, as a generation, are very close to the recent events in Cyprus and we are emotionally charged. Maybe later generations who will not remember or be told about the events as we are. Have you visited the occupied areas? No. I refuse to present my passport for control not by my government, in my own country.

I consider it illogical, even though I have roots in the occupied areas, as my parents come from Famagusta. Have your parents visited Famagusta? Yes, they have. 
To see their house. What was their experience? My father was offered coffee by the Turkish Cypriot now occupying his house.

But this doesn't change things. He has taken over his house. For me it's different. I don't want to visit Kyrenia, Famagusta, Morphou, as I never lived in them before.

I don't know them. That is why, yes I don't identify with them and I feel my identity is territorial. It is restricted to this piece of Cyprus where I live.

Do you find yourself thinking in terms of "Us" and "Them" as to Turkish Cypriots? Yes, and I believe all Greek Cypriots do it.

It is natural. Also as to other cultures living in Cyprus? Yes. I am a racist. Can you explain that? Yes. I don't believe that we as Greeks are superior to other cultures, but there are too many people from other cultures living today in Cyprus. It is turning into a colony.

For such a small place to have so many - about one third of its population coming from other countries and cultures, this poses a threat. That some day, we will become a minority and all the others a majority.

Do you ever catch yourself thinking of "Us" Greek Cypriots and "Them", Turkish Cypriots? Yes.

Do you also think that of other nationalities in Cyprus, like Armenians, Maronites, Asians, Arabs? Not so much.

Why specifically then the Turkish Cypriots? It is our history, the way we have been brought up.

Young people like me, are not, we are not to be blamed for what happened.

But things must change before feelings change. I must feel and they must feel that we are family.

Right now I don't feel that. I feel a Greek Cypriot and look on them as Turkish Cypriots. Do you believe the unsolved Cyprus problem is very much responsible for this? Yes, I believe so, very much.

I don't know any other Turkish Cypriots aside from the three I have mentioned. Yes, I do discriminate between "them" and "us". Yes I do believe we can coexist.

As to other cultures like Asians, Pakistanis, Russians in Cyprus, them, I consider as complete strangers. With Turkish Cypriots we have more in common. Yes, I think in those terms.

I believe it is because of the Turkish invasion and all the stories that happened then about which we hear from our parents. As to the exchange students, it is 
interesting to observe that they also thought in terms of "Us" and "Them", saying that they had been influenced by the Greek-Cypriot students and society and that the backwardness of the other side reinforces this negative thinking.

\section{CONCLUSIONS}

Buying through the Internet, although present, did not seem to be a very strong trend. Contrariwise, there were strong reservations as regards the quality, the standard, if not the price of the ordered goods. So lifestyle habits of buying from shops or through the traditional media ads seemed to prevail as yet among the sample.

Job-seeking and professional pursuits on the net and especially through Facebook did not, either seem to be a main point of interest with the interviewed sample, who seemed to be very focused as to what they were looking for and where, as regards the pursuit of employment or the furthering of their professional engagement. The way they spoke about jobs traced through Facebook - modeling and serving coffee - also insinuated a hidden doubt about job seeking on Facebook, or on the Internet generally.

Participation in either the Causes on Facebook or other similar serious group activities, on Facebook or in civic activities in actual life again seemed to be limited. The sample seemed to be involved rather superficially in occasional philanthropic gestures, like contributing money to collections, or signing for some kind of protest, but very few were consistently involved in groups that tried to tackle, as campaigners, either local or global problems.

As to political participation, even though there was a rather strong response to voting, actual involvement in politics was very limited, and a lack of trust in political parties and institutions, all created in Cyprus during its last 50 years of independence, reminds one of Castell's (2004) statement that: "When new political institutions are creat-ed, or recreated, they are defensive trenches of identity, rather than launching platforms of political sovereignty." This reality, according to the author (ibid:34) leads to the creation of a cultural nationalism, whereby: "... the cultural nationalist regards the nation as a product of its unique history and culture, and as a collective solidarity endowed with unique at- tributes. In short, cultural nationalism is concerned with the distinctiveness of the cultural community as the essence of a nation".

Perhaps this cultural nationalism surfaced eventually in the 27 interviews of this project, as it became clear that inspite of the internet experience and the substantial use of a transborder platform like Facebook, the identity of this age group seems to be bound up with the life world in the territories of the Cyprus Republic, not the whole of the island, which, besides they never experienced themselves. 
To remind ourselves of Manuel Castells (2004, p.57) "ethnicity is being specified as a source of meaning and identity, to be melted not with other ethnicities, but under broader principles of cultural self-definition, such as religion, nation and gender". The historical context or even the "territorial historicity" in which people develop and progress plays a very important role in shaping their collective memory.

Even in the cases where the interviewees have met Turkish-Cypriots on Facebook, their acceptance of them in real life is very meager, reminding us of Smith's comment (in Mackay and Sullivan, eds. 1999, p.96) that: "The depth and weight of national cultures, symbols and ideas of national cultures, cannot measure up to those which purport to be global"..but the latter ...tend to lack history and depth and are not anchored or shared in everyday life and experience."

In the case of Cyprus, of course we cannot describe the localized ethnicity of Greek-Cypriotness, as a phenomenon of "defensive trenches of identity" a reaction against "global elites" which Castells (2004, p. 34) marks in other countries, but it could be a reaction against the immediate threat of the invasion and the continuing occupation, which has become a cumulative experience in the collective consciousness of the Greek-Cypriots, thus affecting on a group level their social representations. It can, in other words be an ethnic nationalism that is "defensive and reactive, but not proac- tive, functioning as a refuge and solidarity to protect against a hostile outside world" (Ibid, p.68) (in Cyprus a neighbouring, threatening world).

This defensiveness came through very strongly when Identity and Otherness were explored, as the interviewees felt strongly this divisional differentiation between them and the Turkish-Cypriots, the entire set of feelings being framed against the backdrop of a territorial identity that decries division and occupation as illegal and threatening factors. This is where identity politics in the corporeal world (in Cyprus) take leave of expected or anticipated (globazlized) identity politics on the Internet and in particular among, perhaps, Facebook users. The local identity supersedes any extension of the self over time and space, with reactions, responses, feelings and attitudes being generated by the local geographical and political realities on the island, harsh and unchanging for the last 37 years.

The conclusions from this project are one more addition to similar conclusions by other research projects about the identity of young people in Cyprus conducted during the last 10 years or so.

In 1997, in a research report on "Television and the Cultural Identity of Cyprus Youth" (Roussou, 2001, p.132 ) the self-stated identity of young Greek-Cypriots 1318 , showed " $48 \%$ feeling Greek-Cypriots and 18.8\% Cypriots." In 2006, $43 \%$ of youth surveyed (48\% of Greek-Cypriots and 39\% Turkish-Cypriots identified themselves as "Cypriots" (Cyprus Human Development Report, 2009 XIV), however, " $a$ closer examination of the term "Cypriot" revealed that a striking $86 \%$ of GreekCypriots and a corresponding 55\% of Turkish-Cypriots, when using the term "Cyp- 
riot" refer exclusively to Greek-Cypriots or Turkish-Cypriots respectively (i.e. to their own ethnic community and not to all Cypriots."

Furthermore, as mentioned earlier in our introduction, the present researchers in their paper on youth and new communication technologies (2008) came to some very relevant conclusions, which are being repeated in the present paper. Namely that "In spite of Europeanization and globalization, the celebration of the end of nationalism, as mentioned earlier, seems to be premature" (p. 264). And: "One of the most worrisome aspects though in the results of this survey which deserves further research is young people's avoidance to contribute to the public sphere in real life, as very few seemed to be active in any specific social, political, or cultural areas" (p. 264).

Perhaps Castells is right in coming to the following conclusion about contemporary identities. Identities which, in the context of internet communication, adopt virtual fish pets and engage in virtual restaurants, but on an intensive scale respond defensively to the situation prevailing in Cyprus with its individual local geo-political particularities: "Local communities, constructed through collective action and preserved through collective memory, are specific sources of identities. But these identities, in most cases are defensive reactions against the impositions of global disorder and uncontrollable, fast-paced change. They do build havens, but not heavens" (2004, p. 68).

Conclusively it is true that, as mentioned in the introduction of this research paper the Internet has provided a new way of creating communities that extend beyond geographic boundaries (Kraut et al., 2002), and can be a new venue for youth to engage in civic and volunteering activities across local communities and national frontiers. Young people can learn through it about political life and experience the challenges and rewards of democratic participation (Camino and Zeldin, 2002). Nevertheless, there is perhaps reason in what writers like Hafez (2007, p. 117) maintain that "the Internet is an important but overestimated medium, always in relation to real, life world local and geo-political factors."

\section{BIBLIOGRAPHY}

Bell, B. L. (2005), "Children, Youth, and Civic (dis)Engagement: Digital Technology and Citizenship", CRACIN Working, Paper, No. 5, Available: http: www. cracin.ca (Accessed September 29, 2009).

Benn, J. (2004), "Consumer education between 'consumership' and citizenship: experiences fromstudies of young people", International Journal of Consumer Studies, Vol. 28, pp. 108-116.

Boyd, D. (2008), "Why youth (heart) social network sites: The role of networked publics in teenage social life" in D. Buckingham (Ed.), Youth, Identity, and Digital Media, MIT Press, Cambridge, MA, pp. 119-142. 
Boyd, D., Ellison, N., (2007). Social Network Sites: Definition, History, and Scholarship", Journal of Computer-Mediated Communication, Vol. 13, No. 1, pp. 2120-230.

Camino, L., Zeldin, S. (2002), "From periphery to center: Pathways for youth civic engagement in the day-to-day life of communities", Applied Developmental Science, Vol. 6, No. 4, pp. 213-220.

Castells, M. (2004), The Power of Identity, Blackwell Publishing, UK.

Cyprus Human Development Report (2009), Youth in Cyprus: Aspriations, Lifestyles and Empowerment.

Hafez, K. (2007), The Myth of Media|Globalization, Polity Press, Cambridge, UK.

Kenway, J., Langmead, D. (2000), "Cyberfeminism and citizenship? Challenging the po-litical imaginary" in M. Arnot \& J.A. Dillabough (Eds.), Challenging democracy: International perspectives on gender, education and citizenship, RoutledgeFalmer, New York, pp. 312-329.

Kraut, R., Kiesler, S., Boneva, B., Cummings, J. (2002), "Internet paradox revisited.", Journal of Social Issues, Vol. 58, No. 1, pp. 49-74.

Kvale, S. (1996), „The social construction of validity“, in Interviews, Sage, Thousand Oaks, CA.

Livingstone, S. (2003), "Children's use of the internet: Reflections on the emerging research agenda", New Media \& Society, Vol. 5, No. 2, pp. 147-166.

Montgomery, K., Gottlieb-Robles, B., Larson, G.O. (2004), Youth as e-citizens: Engaging the digital generation, School of Communication, American University, Washington, DC: Center for Social Media, Available from: http://www. centerforso-cialmedia.org/ecitizens/youthreport.pdf (Accessed 25.03. 2010).

Papaioannou.T., Roussou.N. (2006), "The Internet and Young People's Sociability: Continuums or Reversals?" in N. Leandros (Ed.), The Impact of the Internet on the Mass Media in Europe, Arima Publishing, UK, pp. 191-206.

Papaioannou. T., Roussou, N. (2009), "Young People and New Communication Technologies: Cross-Media Consumption and Its Effects on Cognitive and Affective Development" in Y. Pasadeos Ed., Variety in Mass Communication Research ATIN-ER, Athens, Greece, pp. 251-272.

Roussou. N. (2001), Television and the Cultural Identity of Cyprus Youth, Unpublished dissertation for University of Coventry 